\title{
Comparative Analysis of Al-Li Alloy and Aluminum Honeycomb Panel for Aerospace Application by Structural Optimization
}

\author{
Naihui Yu, ${ }^{1}$ Jianzhong Shang, ${ }^{1}$ Yujun Cao, ${ }^{1}$ Dongxi Ma, ${ }^{2}$ and Qiming Liu ${ }^{3}$ \\ ${ }^{1}$ College of Mechatronics Engineering and Automation, National University of Defense Technology, Changsha 410073, China \\ ${ }^{2}$ Ordnance Technology Institute, Ordnance Engineering College, Shijiazhuang 050003, China \\ ${ }^{3}$ College of Mechanical and Vehicle Engineering, Hunan University, Changsha 410082, China \\ Correspondence should be addressed to Jianzhong Shang; jz_shang_nudt@163.com
}

Received 5 July 2015; Revised 8 September 2015; Accepted 9 September 2015

Academic Editor: Mohammed Nouari

Copyright (C) 2015 Naihui Yu et al. This is an open access article distributed under the Creative Commons Attribution License, which permits unrestricted use, distribution, and reproduction in any medium, provided the original work is properly cited.

\begin{abstract}
Al-Li alloy and aluminum honeycomb panel (AHP) are both excellent materials for aeronautical structures. In this paper, a platetype aeronautical structure (PAS), which is a base mounting structure for $172 \mathrm{~kg}$ functional devices, is selected for comparative analysis with different materials. To compare system-level performance under multidisciplinary constraints, mathematical models for optimization are established and then structural optimization is carried out using Altair OptiStruct. For AHP, its honeycomb core is regarded as orthotropic material and its mechanical properties are calculated by Allen's model in order to establish finite element model (FEM). The heights of facing sheet and honeycomb core are selected as design variables for size optimization. For $\mathrm{Al}-\mathrm{Li}$ alloy plate, topology optimization is carried out to obtain its most efficient load path; and then a reconstruction process is executed for practical manufacturing consideration; to obtain its final configuration, accurate size optimization is also used for reconstructed model of Al-Li alloy plate. Finally, the optimized mass and performance of two PASs are compared. Results show that AHP is slightly superior to Al-Li alloy.
\end{abstract}

\section{Introduction}

With the development of aerospace technology, the demand of high-strength-low-density materials is becoming more and more urgent. Severe mechanical environment and aerodynamic coupling are inevitable because of high launch acceleration and high frequency vibration, so the requirements for strength and stiffness of aeronautical structures are extremely high. Moreover, launch costs have strong restrictions on the overall mass of spacecraft, so the mass of aeronautical structures must be minimized as far as possible. Severe contradiction between strength and mass spurs extensive utilization of advanced alloy material and composite material in aerospace applications, such as aluminum lithium (Al-Li) alloys [1], titanium alloy [2, 3], carbon fiber/epoxy composites, and aramid fiber/epoxy composites $[4,5]$. The Al-Li products offer opportunities for significant improvements in aerostructural performance through density reduction, stiffness increase, increases in fracture toughness and fatigue crack growth resistance, and enhanced corrosion resistance [6]. It has been found that addition of $1 \%$ of lithium to aluminum reduces alloy density up to $3 \%$ and increases modulus by 6\% [7]. Besides, a basic trend towards increased utilization and integration of laminated anisotropic composites into the construction of aeronautical and aerospace vehicles has manifested in the last decade [8]. And sandwich-type honeycomb panel [9] which is a typical laminated anisotropic composite is an important alternative aeronautical material. Due to their high strength-to-weight ratio and stiffness-to-weight ratio, the use of honeycomb panels is particularly attractive in various aeronautical structures $[10,11]$.

Since high-strength alloy material and honeycomb panels are both excellent options for aeronautical structures, it is necessary to conduct a comparative analysis under same boundary conditions and load case. Currently, most researches concentrate on the performance of separate material $[12,13]$, but there are very few systematic studies on 


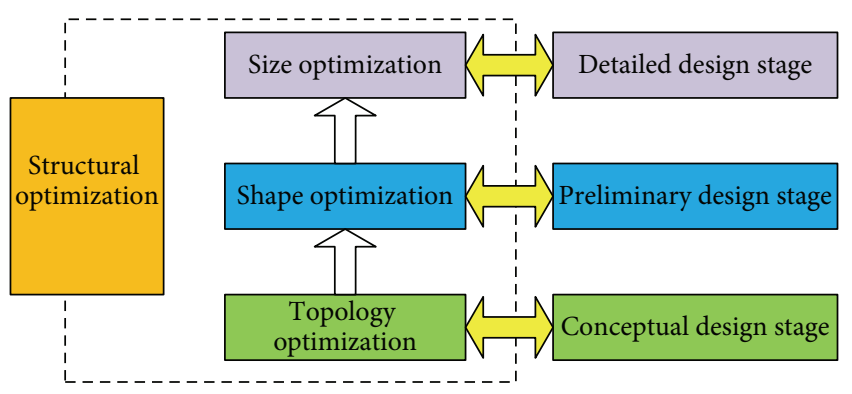

FIgURE 1: Three levels of structural optimization.

the performance comparison of AHP and Al-Li alloy. Aeronautical structures usually have multidisciplinary requirements like minimum mass, high strength and stiffness, eased manufacturing and assembly techniques, and functional needs [14]. In the design of aeronautical structures, choosing what kind of materials is one of the key problems which must be considered firstly. However, it may be a very challenging task even for sophisticated designers only based on their professional knowledge and experience. The choice of materials directly determines the dimension design of structures, its processing methods, and even configurations of structures, especially when the honeycomb panels are in the scope of selection. As a laminated cellular structure, honeycomb panel is a type of structural material considering lightweight design and is a typical anisotropic material, so it cannot be directly compared with alloy material. Performance comparison is meaningful only when the optimal structures of two materials are obtained under the same conditions. Therefore, after the functional loads and performance constraints are almost confirmed, structural optimization technology is needed to obtain the eventual configurations.

In structural optimization, design variables can be categorized into three groups as topology, shape, and sizing variables. Topological design variables determine an initial structural layout whereas shape and sizing parameters give the shape and dimensions of structures, respectively [15]. The three levels of structure optimization are shown in Figure 1. Topology optimization is used in the conceptual design stage to obtain an initial structural configuration and to optimize material layout within a given design space for a given set of loads and boundary conditions such that the resulting layout meets a prescribed set of performance targets. Shape optimization belongs to preliminary design stage. By modifying the structural boundaries, for example, detailed designs for notches, holes, and fillets, concerned mechanical performances are improved during the optimization procedure [16]. Size optimization is used in a detailed design stage and to determine the ideal thickness of a material based on the performance goals and the forces expected to be placed on the component. In the field of aerospace or aeronautical industry, structural optimization technology is widely adopted for many years and is utilized in the design of most aeronautical structures, such as space station [17], aircraft [18], rockets [19], spacecrafts [20]. Maute and Allen presented a topology optimization methodology for the conceptual design of aeroelastic structures accounting for the fluid-structure interaction and the geometrical layout of the internal structure is optimized by material topology optimization [21]. A topology optimization method is proposed to minimize the resonant response of plates with constrained layer damping treatment under specified broadband harmonic excitations [22]. For honeycomb panels, Ermolaeva et al. [23] presented the application of a structural optimization system to the optimal choice of foams as a core material for sandwiches with aluminum alloy faces. Hansel and Becker [24] present a simple heuristic optimization algorithm implemented by ANSYS-macros to determine weight-minimal laminate structures. However, there are no papers about system-level performance comparison of honeycomb panel and alloy material using structural optimization.

In the current paper, a PAS, which is a base mounting structure for 13 different functional devices, is selected for comparative analysis. High-strength Al-Li alloy and aluminum honeycomb panel are both ideal material for simple PAS, so it is very important for structure designers to determine which material is more superior. The commercial finite element package HyperMesh and OptiStruct 8.0 [25] are used for structural optimization. Final size optimization of facing sheet and honeycomb core heights could be directly executed for comparative analysis, as the configuration of honeycomb core is almost definite. The pure Al-Li alloy plate needs topology and size optimization to obtain the optimized configuration. Mathematical models for optimization are established and the mass of structure is chosen as objective function. The rest of the paper is organized as follows. Section 2 briefly introduces the platetype aeronautical structure and its performance requirements considering the launch conditions. Section 3 introduces the structure of AHP and presents its calculation method of orthotropy mechanical properties based on Allen's model, which is important to established its finite element model; the mathematical models for structural optimization are also presented for AHP and Al-Li alloy. Section 4 presents the results of structural optimization and comparative analysis.

\section{Plate-Type Aeronautical Structure and Its Performance Requirements}

Figure 2 shows a typical PAS which is often used in a spacecraft. $X$ direction is rocket's flight direction. Assume that 13 different function devices which form an independent subsystem are installed on this PAS and their total weight is $172 \mathrm{~kg}$. After the layout of these function devices is determinate, the first thing which must be decided by the structural designers is to select materials for this PAS. According to the requirement of installing space, the dimension of PAS is confirmed and the width $M$ and the length $L$ are $980 \mathrm{~mm}$ and $1075 \mathrm{~mm}$, respectively. Two lengths of this rectangle are fixed when the rocket launches. According to the rocket launching environment, performance constraints of the system are given and are shown in Table 1 , where $G$ is $9.81 \mathrm{~m} / \mathrm{s}^{2}$. 
TABLE 1: Performance constraints of the subsystem and its PAS.

\begin{tabular}{|c|c|c|}
\hline Performance & Input loads & Requirement \\
\hline Strength and stiffness & $\begin{array}{l}X \text { direction: } 16.2 G \text { acceleration field } \\
Y \text { direction: } 12.9 G \text { acceleration field } \\
Z \text { direction: } 9.5 G \text { acceleration field }\end{array}$ & $\begin{array}{l}\text { Safety factor is not lower than } 1.5 \\
\text { Maximum deformation is less than } 0.3 \mathrm{~mm}\end{array}$ \\
\hline Resonance frequency & No external input load & Fundamental frequency is not less than $115 \mathrm{~Hz}$ \\
\hline Harmonic response & $\begin{array}{l}X \text { direction: } 7.5 G * \sin (\omega t) \text { harmonic excitation } \\
Y \text { direction: } 5.7 G * \sin (\omega t) \text { harmonic excitation } \\
Z \text { direction: } 4.2 G * \sin (\omega t) \text { harmonic excitation } \\
\text { Frequency } \omega \text { is changing from } 0 \mathrm{~Hz} \text { to } 100 \mathrm{~Hz}\end{array}$ & $\begin{array}{l}\text { Maximum acceleration of function devices is } \\
\text { not more than } 22 G\end{array}$ \\
\hline Mass & All external input loads & $\begin{array}{l}\text { Not more than } 30 \% \text { of total mass of function } \\
\text { devices }\end{array}$ \\
\hline
\end{tabular}

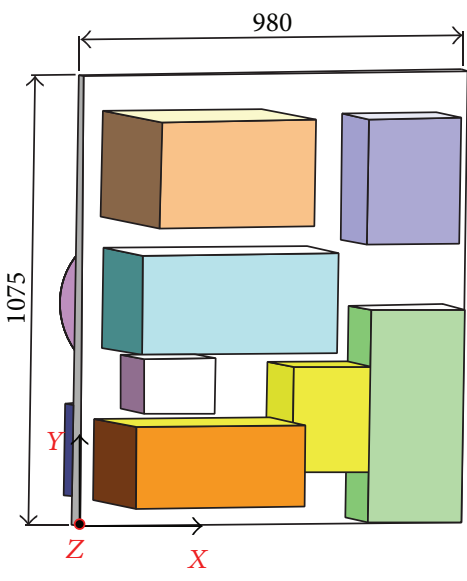

(a) Front

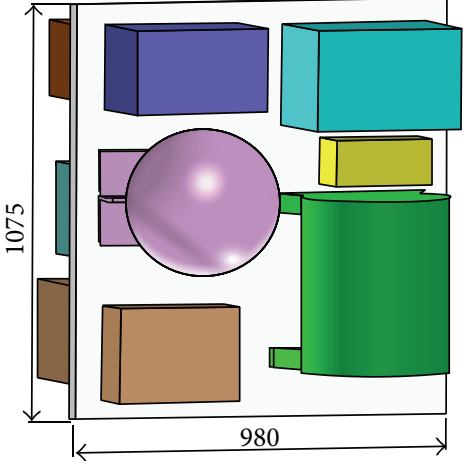

(b) Back

FIgURE 2: Typical PAS and layout of function devices installed on PAS.

Because the frequency range of harmonic response is $0 \mathrm{~Hz} \sim 100 \mathrm{~Hz}$, mechanical resonance will not happen as the fundamental frequency of subsystem is not less than $115 \mathrm{~Hz}$. Therefore, harmonic response constraints need not be considered in the procedure of structural optimization and performance verifications should be carried out after optimized analysis. Lightweight design is one of the most important tasks of structure design for aerospace applications, so the mass of PAS should be selected as optimization objective and structural stress, deformation, and the first order modal as design constraints.

$\mathrm{AHP}$ and $\mathrm{Al}-\mathrm{Li}$ alloy are very different aeronautical materials. AHP is a kind of typical structured material and its configuration is almost determinate, so only size optimization is needed to obtain its optimized structure. Different optimization methods for AHP and Al-Li alloy are shown in Figure 3. Software types used in the paper are SolidWorks for geometry creation, HyperMesh for meshing, OptiStruct for optimization, and HyperView for postprocessing. CAD models of function devices and PAS created in SolidWorks are imported into the HyperMesh for preprocessing. Preprocessing of models includes creating FE model, selection of material properties, creation of load, and applying boundary conditions on model. For AHP, HyperLaminate module is used to model this orthotropy material. For the optimization purpose, optimization criteria are selected. According to criteria, the designable and nondesignable portions are generated. The optimization process is executed in OptiStruct and the result can be viewed in HyperView.

\section{Finite Element Models and Mathematical Models for Structure Optimization}

3.1. Honeycomb Panels. Honeycomb panel, which is shown in Figure 4, is a sort of sandwich panel consisting of two alloy or composite plates as face sheet and hexagonal honeycomb cell as core materials, bonded together by bonding adhesive or macromolecule lamination film. In the sandwich construction, the facing sheets are spaced to provide most of the bending rigidity. They also resist all or nearly all the applied edgewise loads and flatwise bending moments. The core material spaces the facing sheets and transmits shear between them so that they are effective about a common neutral axis. The core also provides most of the shear rigidity of the construction. The core-to-facing bonding adhesive must be adequate to transfer the stresses from the facing sheets to the core materials so that the full properties of the two are utilized [10]. 


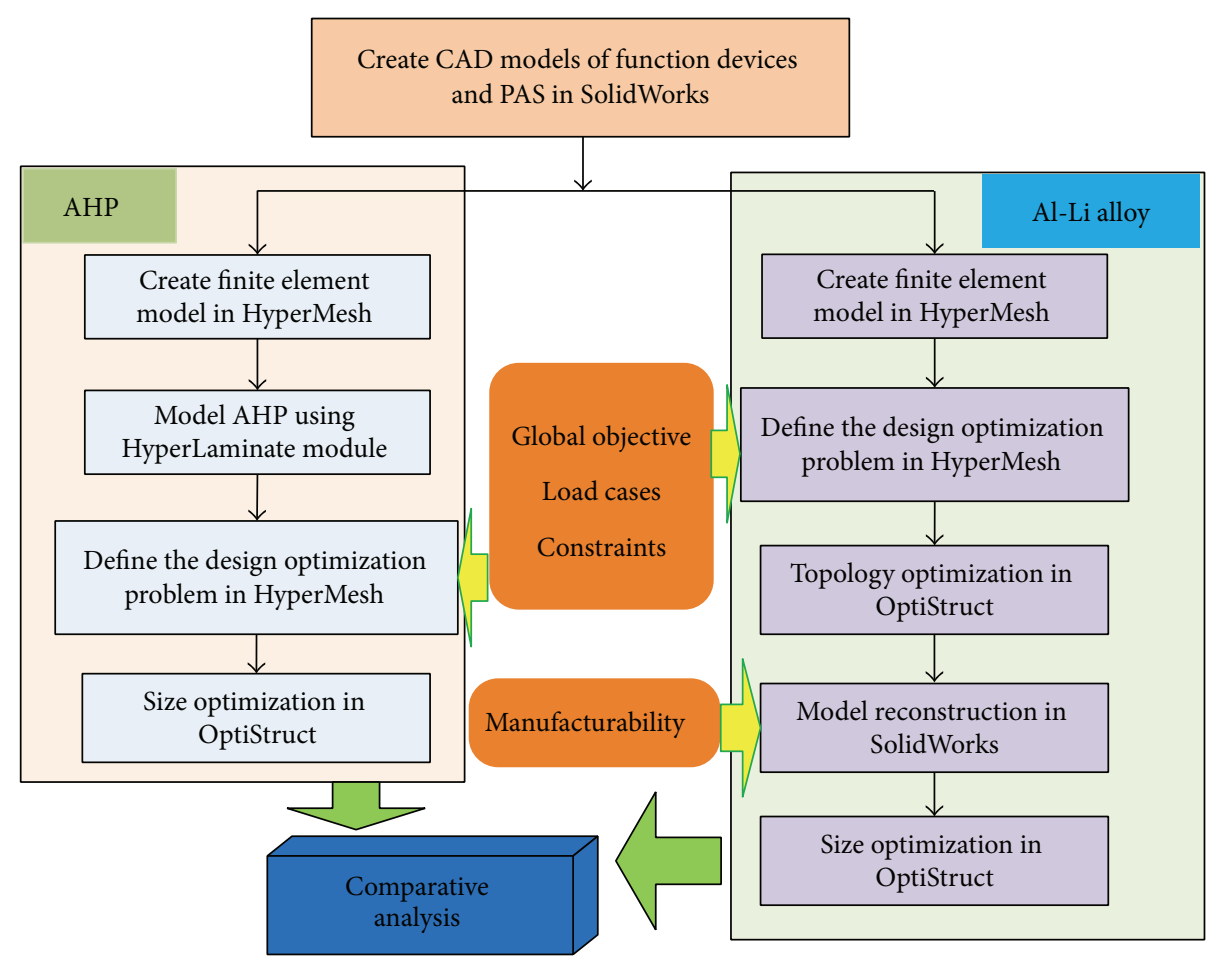

FIGURE 3: Different optimization methods for AHP and Al-Li alloy.

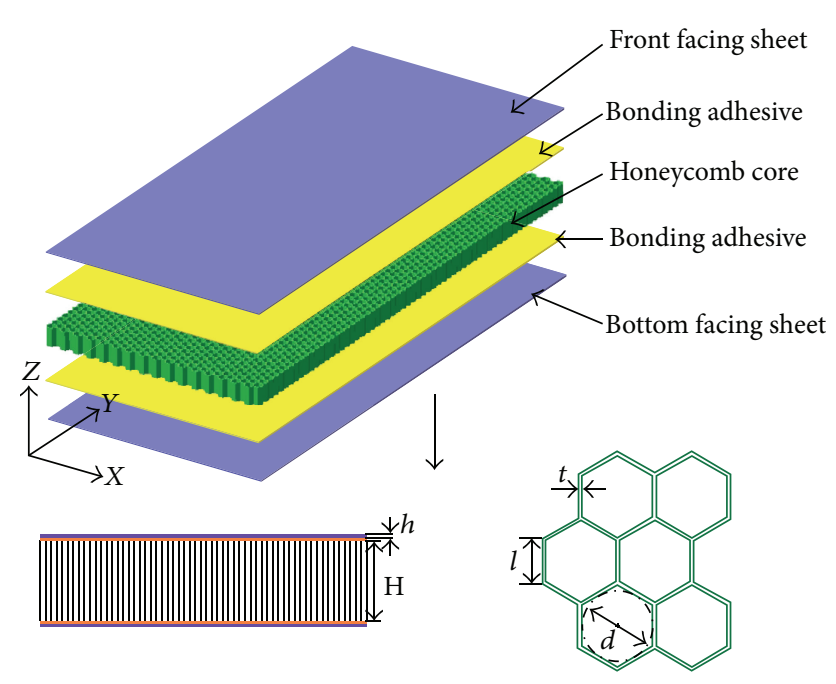

FIGURE 4: Typical structure of hexagonal honeycomb panel and its dimensions.

As shown in Figure 4, $\mathrm{H}$ is the height of hexagonal honeycomb core and $h$ is the height of facing sheet. For hexagonal cell, $t$ is cell wall thickness, $l$ is cell wall width, and $d$ is the diameter of inscribed circle of hexagon. In the process of optimization analysis, 2A12-T4 aluminum alloy is selected as the material of facing sheet. Honeycomb core is aluminum hexagonal honeycomb 1/8-2024-0.003 of Hexcel Corporation, in which $1 / 8$ (inch) represents the diameter of inscribed circle of hexagon, 2024 is its material grade, and 0.003 (inch) represents cell wall thickness. So the cell wall
TABLE 2: The mechanical properties of 2A12-T4 and 2024.

\begin{tabular}{lccccc}
\hline $\begin{array}{l}\text { Material } \\
\text { grade }\end{array}$ & $\begin{array}{c}\text { Density } \\
{\left[\mathrm{kg} / \mathrm{m}^{-3}\right]}\end{array}$ & $\begin{array}{c}\text { Young's } \\
\text { modulus } \\
{[\mathrm{MPa}]}\end{array}$ & $\begin{array}{c}\text { Shear } \\
\text { modulus } \\
{[\mathrm{MPa}]}\end{array}$ & $\begin{array}{c}\text { Poisson's } \\
\text { ratio }\end{array}$ & $\begin{array}{c}\text { Yield } \\
\text { strength } \\
{[\mathrm{MPa}]}\end{array}$ \\
\hline 2A12-T4 & 2780 & 70600 & 28000 & 0.33 & 280 \\
2024 & 2700 & 73000 & 28000 & 0.44 & 75.8 \\
\hline
\end{tabular}

width $l$ could be simply calculated by the equation $l=d$. $\tan (30)$ and its value is $1.83 \mathrm{~mm}$ after unit conversion. The mechanical properties of $2 \mathrm{~A} 12-\mathrm{T} 4$ and 2024 are shown in Table 2.

In order to establish finite element model of honeycomb panels, honeycomb core can be equivalent to orthotropic material and its mechanical properties be calculated by Allen's model [26] which is widely used in mechanical engineering [27]:

$$
\begin{gathered}
E_{x}=E_{y}=\frac{4}{\sqrt{3}}\left(\frac{t}{l}\right)^{3} E, \\
G_{x y}=\frac{\sqrt{3} \gamma}{2}\left(\frac{t}{l}\right)^{3} E, \\
G_{x z}=\frac{\sqrt{3} \gamma}{2} \frac{t}{l} G, \\
G_{y z}=\frac{\gamma}{\sqrt{3}} \frac{t}{l} G, \\
u_{x y}=0.33,
\end{gathered}
$$

where $E$ is Young's modulus of honeycomb core, $G$ is shear modulus, $\gamma$ is a correction factor, and its value depending 
TABLE 3: Equivalent mechanical parameters of 1/8-2024-0.003.

\begin{tabular}{lccccc}
\hline$E_{x} / \mathrm{MPa}$ & $E_{y} / \mathrm{Mpa}$ & $G_{x y} / \mathrm{MPa}$ & $G_{x z} / \mathrm{MPa}$ & $G_{y z} / \mathrm{MPa}$ & $u_{x y}$ \\
\hline 11.3 & 11.3 & 1.7 & 370.2 & 246.6 & 0.33 \\
\hline
\end{tabular}

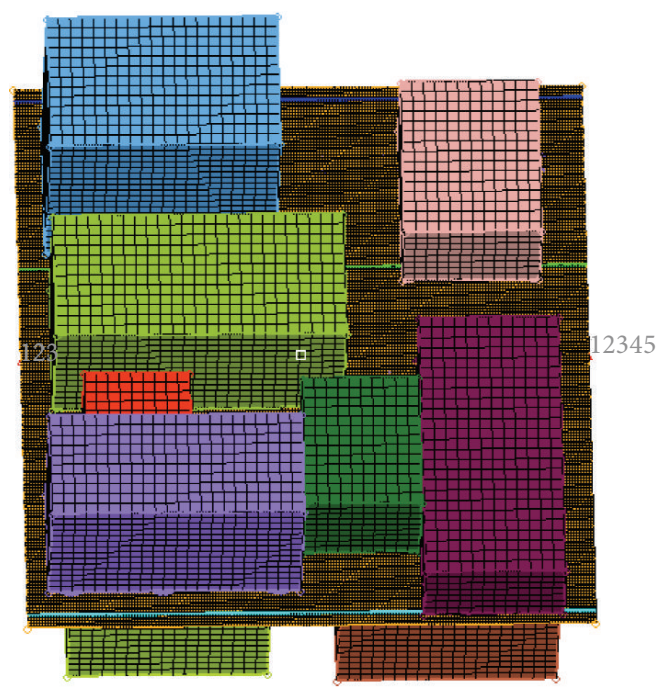

FIgURE 5: Finite element model of subsystem with honeycomb panel.

on the manufacturing process is generally $0.4 \sim 0.6$. By the equivalent calculation, mechanical parameters of aluminum hexagonal honeycomb are shown in Table 3.

A finite element model of this subsystem is established using Altair OptiStruct. Honeycomb panel is meshed in HyperMesh using four-noded linear quad elements (CQUAD4) and composite properties are applied, where the core is orthotropic material and the sheets are isotropic material. All function devices are simplified by shell element and their mass is equivalent to the thickness of shells. Bolt connections are simplified as multipoint constraints and modeled by the flexible unit (RBE3). Two length of honeycomb panel are fixed in all six degrees of freedom. The finite element model is shown in Figure 5.

For structure optimization, performance constraints shown in Table 1 are used and the height of hexagonal honeycomb core $H$ and the height of facing sheet $h$ are selected as the design variables. The mass of subsystem is objective function. And mathematical models for honeycomb panel optimization could be described as

$$
\begin{gathered}
\min _{d} \quad M(d) \\
\text { Subject to: } \quad g_{1}(d)=\sigma_{p} \leq \frac{\sigma_{s}}{S} \\
g_{2}(d)=\varepsilon \leq 0.3 \mathrm{~mm} \\
g_{3}(d)=f_{1} \geq 115 \mathrm{~Hz} \\
d_{\min } \leq d \leq d_{\max },
\end{gathered}
$$

where $M(d)$ is the total system mass, $g(d)$ is performance constraint, $\sigma_{p}$ is the actual stress value while $\sigma_{s}$ is yield
TABLE 4: Lower and upper limit values of design variables.

\begin{tabular}{lccc}
\hline Design variable & $\begin{array}{c}\text { Initial } \\
\text { dimension } \\
{[\mathrm{mm}]}\end{array}$ & $\begin{array}{c}\text { Lower limit } \\
\text { value }[\mathrm{mm}]\end{array}$ & $\begin{array}{c}\text { Upper limit } \\
\text { value }[\mathrm{mm}]\end{array}$ \\
\hline$h$ & 2 & 0.15 & 5 \\
$H$ & 36 & 10 & 100 \\
\hline
\end{tabular}

strength of facing sheet material, $S$ is safety factor and the value is selected as 1.5 in this paper, $\varepsilon$ is maximum deformation of PAS, $f_{1}$ is fundamental frequency of this system, $d$ is design variable and $d=[h, H]$, and $d_{\min }$ and $d_{\max }$ are, respectively, lower and upper limit values of design variables and are shown in Table 4.

3.2. PAS of Al-Li Alloy. The performance of frame structure largely depends on the properties of material. In this paper, Al-Li alloy 2090 is selected for comparative analysis with honeycomb panel while all boundary conditions, input loads, and layout of function devices are identical. 2090 is a kind of high performance material and its elastic modulus increased by about $10 \%$ while the density decreased by about $10 \%$ compared with the conventional aluminum alloy. So its stiffnessto-weight ratio and strength-to-weight ratio are improved remarkably. The mechanical parameters of 2090 versus conventional aluminum alloy $2 \mathrm{All} 2$ are shown in Table 5.

For a plane-frame structure of pure Al-Li alloys, topology optimization is firstly used for a conceptual design proposal and then fine-tuned for manufacturability. Initial thickness of the plane-frame structure is a critical factor for topology optimization and the value of initial thickness directly determined the optimization result. Therefore, four values of initial thickness $(40 \mathrm{~mm}, 50 \mathrm{~mm}, 60 \mathrm{~mm}$, and $70 \mathrm{~mm}$ ) are used, respectively, and the best thickness is determined by comparing the optimum results. At last, size optimization is executed to obtain a desired thickness of plane-frame structure. Similarly with honeycomb panel, Al-Li alloys plate is meshed with four-noded linear quad elements (CQUAD4) and the function devices are meshed in the same way. The finite element model is shown in Figure 6. In order to retain installation points of function devices, the meshed plate will be divided into designable and nondesignable portions. The geometry for the design space is defined by inspection of the bounds. As shown in Figure 5, green areas are selected as nondesignable portions and insure that all fixing points (yellow points) are included.

In the process of topology optimization of Al-Li alloys plate, the initial thickness is defined and the design variable is element density of meshed plate $\rho$. And mathematical model could be described as

$$
\begin{gathered}
\min _{\rho} \quad M(\rho) \\
\text { Subject to: } \quad g_{1}(\rho)=\sigma_{p} \leq \frac{\sigma_{s}}{S} \\
g_{2}(\rho)=\varepsilon \leq 0.3 \mathrm{~mm} \\
g_{3}(\rho)=f_{1} \geq 115 \mathrm{~Hz} \\
\rho \in[0,1] .
\end{gathered}
$$


TABle 5: Mechanical parameters of 2090 versus 2Al12.

\begin{tabular}{lccccc}
\hline Material grade & Density $\rho\left[\mathrm{kg} \cdot \mathrm{m}^{-3}\right]$ & Young's modulus $E[\mathrm{MPa}]$ & Yield strength $\sigma_{s}[\mathrm{MPa}]$ & $\begin{array}{c}\sigma_{s} / \rho \\
{\left[\mathrm{MPa} \cdot \mathrm{m}^{3} / \mathrm{kg}\right]}\end{array}$ & $E / \rho\left[\mathrm{MPa} \cdot \mathrm{m}^{3} / \mathrm{kg}\right]$ \\
\hline 2090 & 2590 & 78600 & 530 & 0.2 & 30.3 \\
2 Al12 & 2780 & 70600 & 280 & 0.1 & 25.4 \\
\hline
\end{tabular}

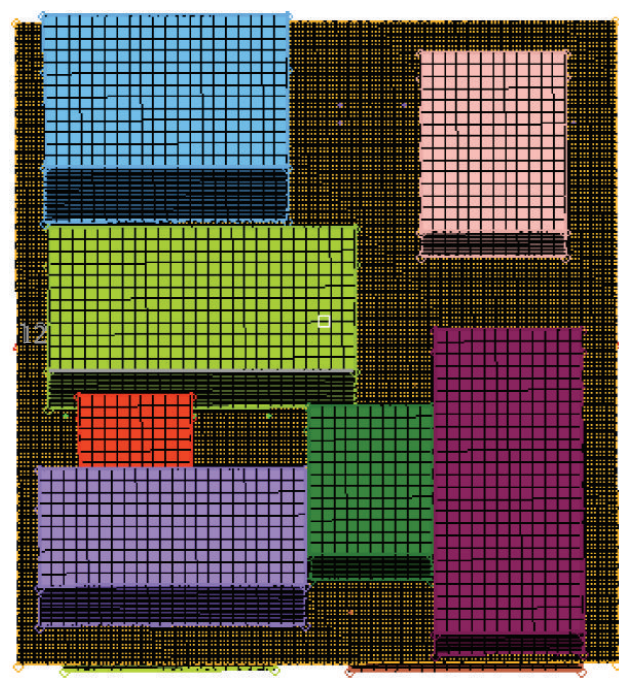

(a) Finite element model

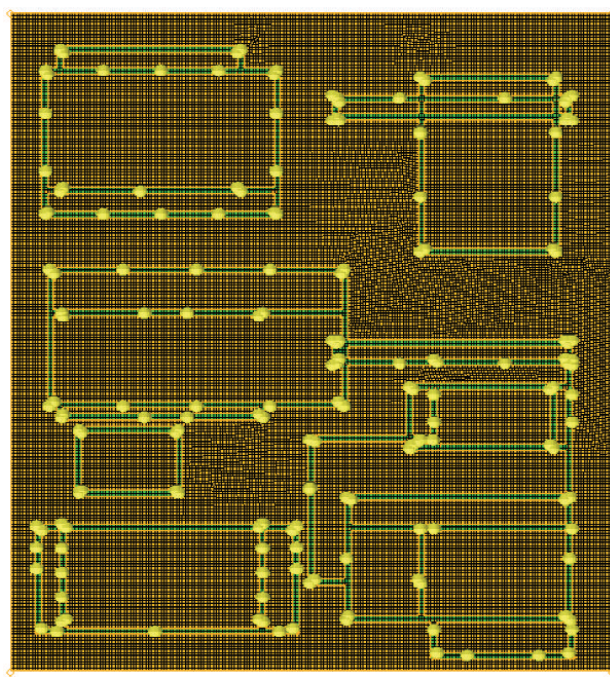

(b) Designable and nondesignable portions

Figure 6: Finite element model for Al-Li alloys structure of PAS.

After topology optimization, size optimization should be carried out to obtain a further optimized thickness of Al-Li alloys plate, so the thickness is selected as design variable and its initial value would be the selected result of topology optimization. The mathematical model of size optimization is shown in

$$
\begin{gathered}
\min _{t} M(t) \\
\text { Subject to: } \quad g_{1}(t)=\sigma_{p} \leq \frac{\sigma_{s}}{S} \\
g_{2}(t)=\varepsilon \leq 0.3 \mathrm{~mm} \\
g_{3}(t)=f_{1} \geq 115 \mathrm{~Hz} \\
t_{0}-10 \leq t \leq t_{0}+10 .
\end{gathered}
$$

\section{Optimization Results and Comparative Analysis}

4.1. Optimization Results of Honeycomb Panel. After seven times of iteration, the results of structure optimization are obtained and shown in Figure 7. The ultimate dimensions of design variables $h$ and $H$ are $1 \mathrm{~mm}$ and $99.4 \mathrm{~mm}$, respectively. The ultimate mass of subsystem is $213.40 \mathrm{~kg}$ and the mass of honeycomb panel is $41.40 \mathrm{~kg}$. However, bolt sockets embedded in honeycomb panel are inevitable and their mass must be taken into account. The number of bolt sockets used to fix function devices by M5 bolt is 103 and the mass of each bolt socket is $0.005 \mathrm{~kg}$. Similarly, the number of bolt sockets used to fix honeycomb panel by M10 bolt is 32 and the mass of each bolt socket is $0.025 \mathrm{~kg}$. Therefore, the total mass of
TABle 6: Maximum von Mises stress and deformation under input loads.

\begin{tabular}{lcc}
\hline Input loads & $\begin{array}{c}\text { Maximum von } \\
\text { Mises stress [MPa] }\end{array}$ & $\begin{array}{c}\text { Maximum } \\
\text { deformation } \\
{[\mathrm{mm}]}\end{array}$ \\
\hline $\begin{array}{l}X \text { direction: } 16.2 G \\
\text { acceleration field }\end{array}$ & 1.822 & 0.086 \\
$Y$ direction: $12.9 G$ \\
$\begin{array}{l}\text { acceleration field } \\
Z \text { direction: } 9.5 G \\
\text { acceleration field }\end{array}$ & 1.795 & 0.05237 \\
\hline
\end{tabular}

TABLE 7: Natural frequencies of first eight order modes.

\begin{tabular}{lcrrrrrrr}
\hline $\begin{array}{l}\text { Mode } \\
\text { order }\end{array}$ & 1 & 2 & 3 & 4 & 5 & 6 & 7 & 8 \\
\hline $\begin{array}{l}\text { Natural } \\
\text { frequency } \\
{[\mathrm{Hz}]}\end{array}$ & 114.8 & 137 & 164.7 & 169.6 & 186.9 & 216.5 & 234.4 & 238.9 \\
\hline
\end{tabular}

bolt sockets is $1.315 \mathrm{~kg}$ and the mass of honeycomb panel including bolt sockets is $42.72 \mathrm{~kg}$, which is $24.84 \%$ of total mass of all function devices. The maximum von Mises stress and deformation of honeycomb panel under input loads of three directions are shown in Table 6.

Modal analysis is carried out after structure optimization, and first two order modes of subsystem are shown in Figure 8. Natural frequencies of first eight order modes are shown in Table 7. Harmonic response analysis is also conducted using 


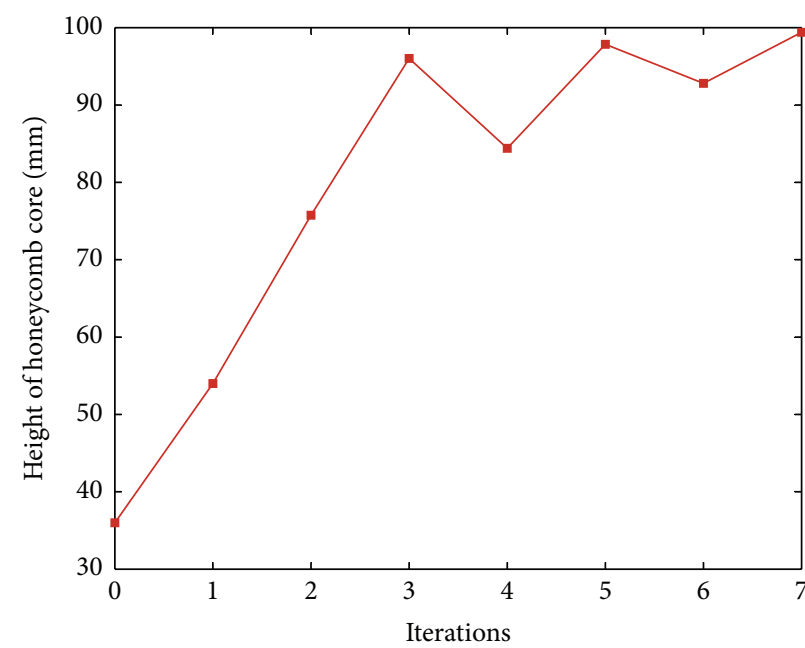

(a) Iterations of core's height

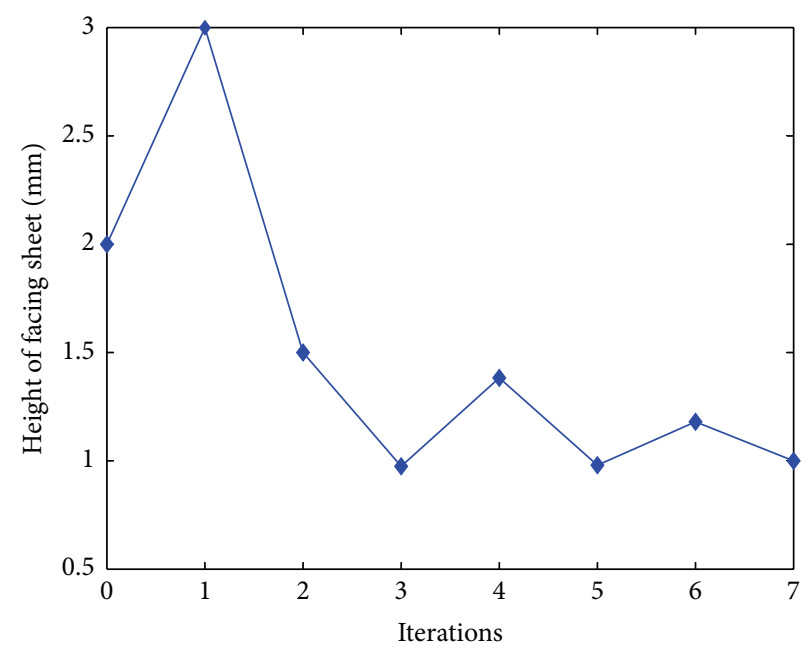

(b) Iterations of facing sheet's height

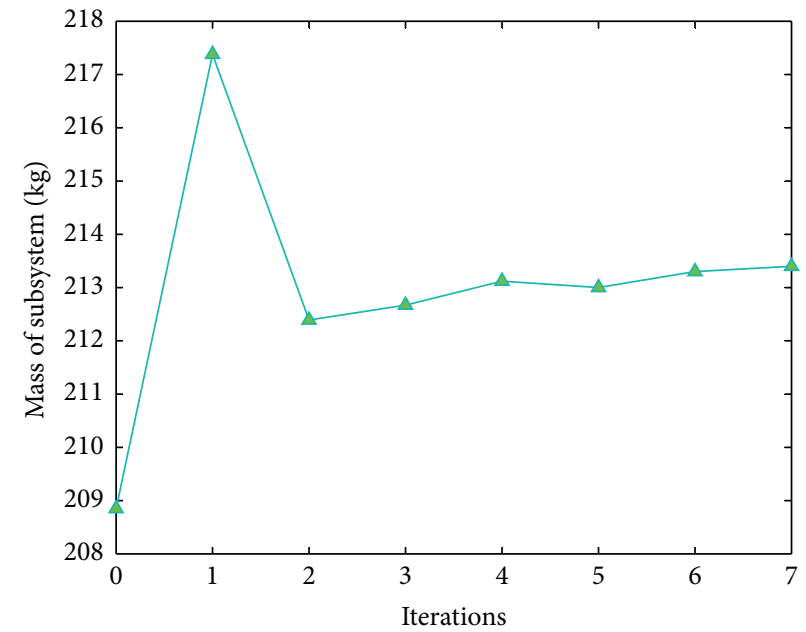

(c) Iterations of subsystem's mass

FIGURE 7: Iterative process curve of honeycomb panel optimization.

\footnotetext{
Contour plot Eigen mode (Mag) Analysis system Simple average

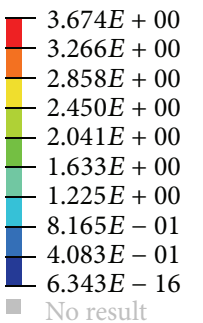

$\operatorname{Max}=3.674 E+00$ Grids 7642

$\operatorname{Min}=6.343 E-16$ Grids 115065
}

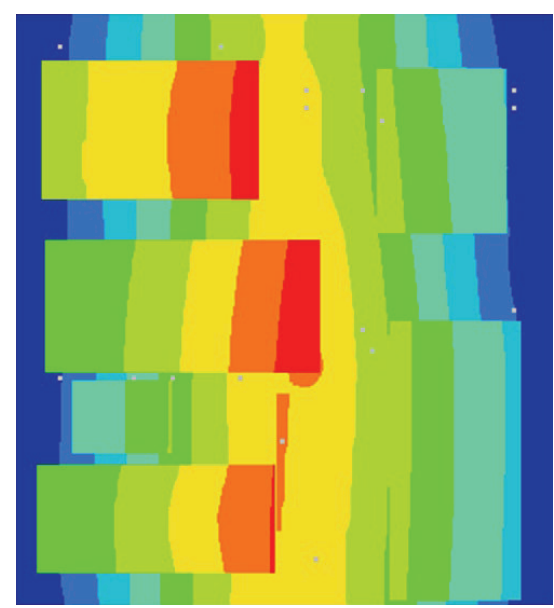

(a) First order mode

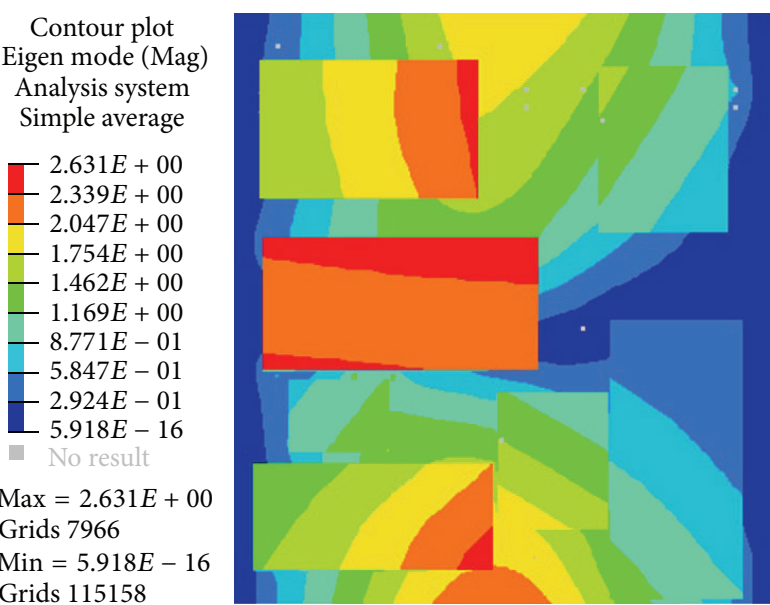

(b) Second order mode

FIgURE 8: First and second order mode of subsystem. 


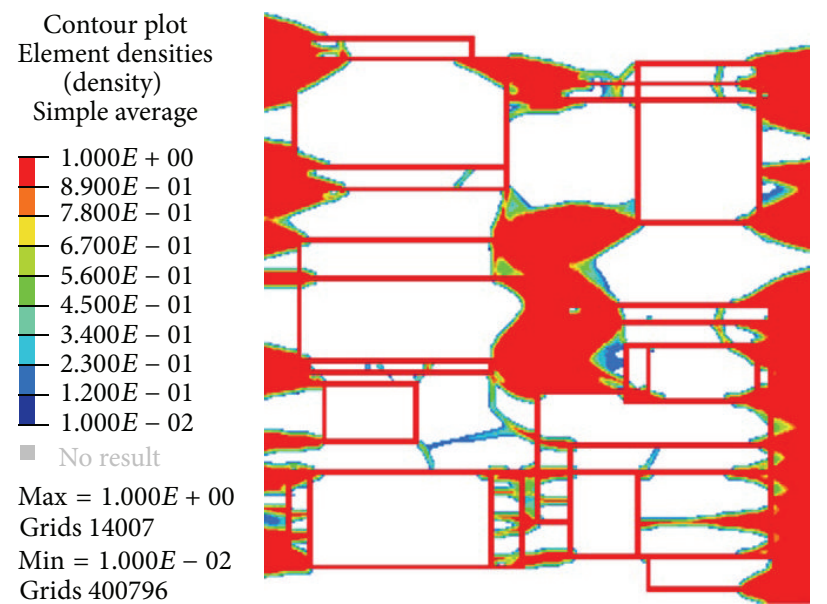

(a) $40 \mathrm{~mm}$

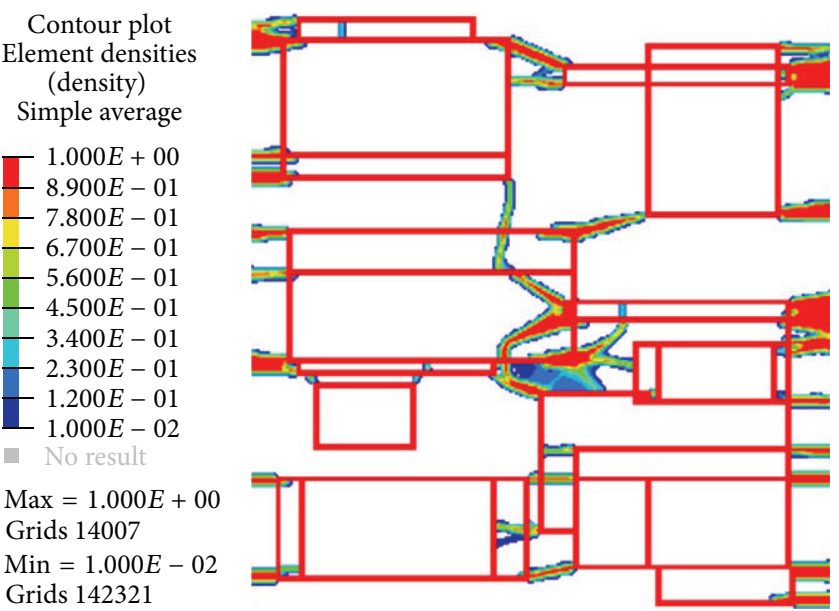

(c) $60 \mathrm{~mm}$
Contour plot Element densities (density)

Simple average

$-1.000 E+00$

$8.900 E-01$

$-7.800 E-01$

$-6.700 E-01$

$-5.600 E-01$

$4.500 E-01$

$-3.400 E-01$

$2.300 E-01$

$1.200 E-01$

$1.000 E-02$

- No result

$\operatorname{Max}=1.000 E+00$ Grids 14007

Min $=1.000 E-02$ Grids 142321

$\begin{gathered}\text { Contour plot } \\ \text { Element densities } \\ \text { (density) }\end{gathered}$
Simple average
1.000E +00
$-8.900 E-01$
$-7.800 E-01$
$-6.700 E-01$
$-5.600 E-01$
$-4.500 E-01$
$-3.400 E-01$
$-2.300 E-01$
$-1.200 E-01$
$1.000 E-02$
No result
Max $=1.000 E+00$
Grids 14007
Min $=1.000 E-02$
Grids 142321
Grids 142321

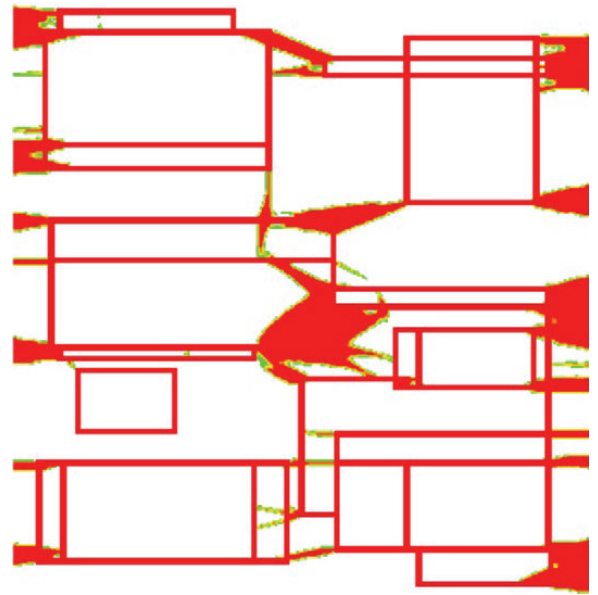

(b) $50 \mathrm{~mm}$

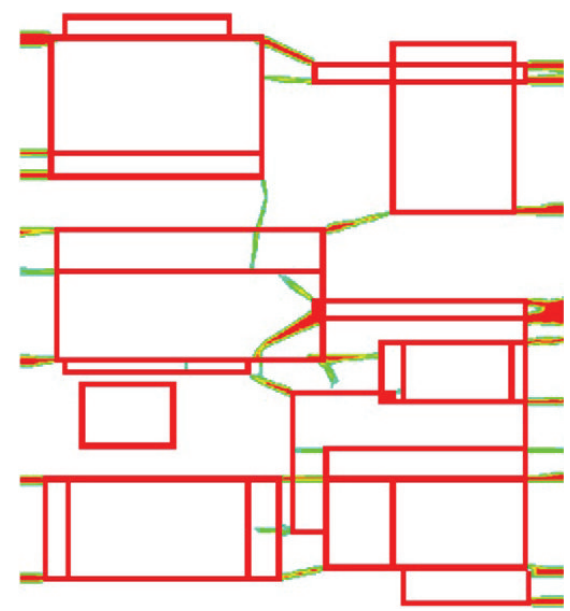

(d) $70 \mathrm{~mm}$

Figure 9: Density contours of Al-Li alloy structure with different thickness.

performance constraints shown in Table 1. Modal damping is a critical parameter for harmonic response. The damping coefficient of composite material is commonly $5 \% \sim 8 \%$ and $6 \%$ is taken for honeycomb panel in this paper. 13 codes of each function device are selected as output nodes during harmonic analysis. The maximum acceleration response of all nodes in $X, Y$, and $Z$ directions is $16.0 G, 9.3 G$, and $18.5 G$, respectively. So the acceleration response cannot exceed the requirement of subsystem, namely, $22 G$.

4.2. Optimization Results of Al-Li Alloy Structure. The topology optimization result using material distribution method is a density distribution of the finite elements in the design domain [16]. Density contours of Al-Li alloy structure are shown in Figure 9. Different thicknesses, $40 \mathrm{~mm}, 50 \mathrm{~mm}$, $60 \mathrm{~mm}$, and $70 \mathrm{~mm}$, are chosen to implement topology optimization.

The iterative process curves of Al-Li alloy structure of different thickness are shown in Figure 10. The ultimate mass of $40 \mathrm{~mm}$ plate is $54.71 \mathrm{~kg}, 50 \mathrm{~mm}$ plate is $48.30 \mathrm{~kg}, 60 \mathrm{~mm}$ plate is $47.43 \mathrm{~kg}$, and $70 \mathrm{~mm}$ plate is $48.54 \mathrm{~kg}$. Therefore, the best thickness is $60 \mathrm{~mm}$ considering the light weight design. And a successive size optimization is necessary to obtain a more optimized thickness. Since boundaries of topology optimization result are discontinuous, the optimized structure cannot satisfy practical manufacturing requirements. So model reconstruction is needed according to density contour. The structure of topology optimization is most efficient load path for various constraints, so reconstructed model would inevitably lead to degrading the performance or augmenting the mass, or even degrading the performance while augmenting its mass. The reconstructed model of Al-Li alloy plate considering manufacturing requirements is shown in Figure 11. All inclined beams or irregular structures are modified to straight ones. In order to enhance the strength of fixed lengths, all of the other color parts of two lengths are changed to red parts. Other details are also adjusted to meet the requirements of processing. The mass of reconstructed plate is $47.23 \mathrm{~kg}$ and slightly lower than original $47.43 \mathrm{~kg}$. Fundamental frequency is $110.7 \mathrm{~Hz}$, so the performance of reconstructed plate degraded and further optimization is needed. 


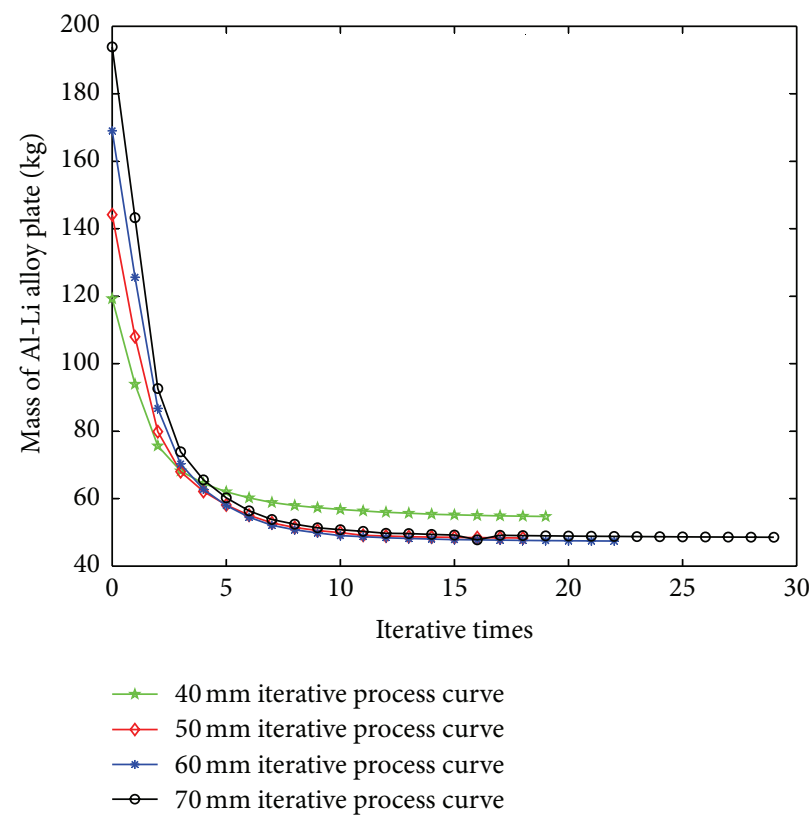

FIGURE 10: Iterative process curve of Al-Li alloy plate with different thickness.
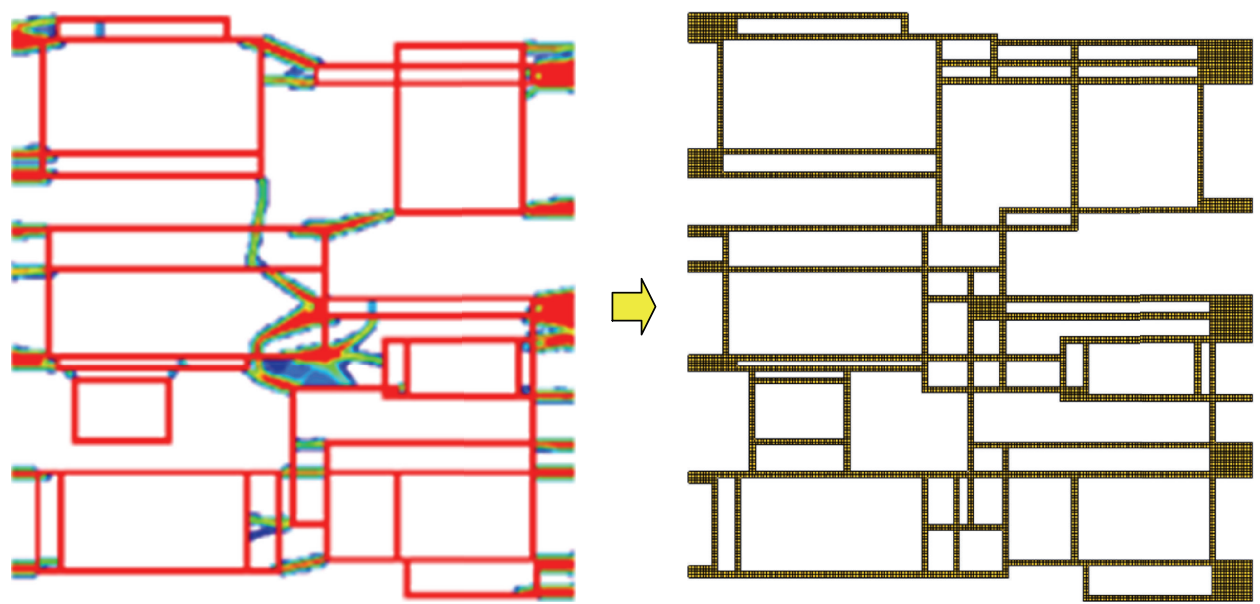

FIGURE 11: The topology optimization modal versus reconstructed model of Al-Li alloy plate.

Size optimization of reconstructed model is carried out based on the mathematical model presented in Section 3.2. After two times of iteration, the optimized thickness of Al$\mathrm{Li}$ alloy plate is got and the value is $62.54 \mathrm{~mm}$. The mass of Al-Li alloy plate increases to $48.39 \mathrm{~kg}$ and the fundamental frequency increases to $115.4 \mathrm{~Hz}$, simultaneously. The maximum von Mises stress and deformation of Al-Li alloy plate under input loads of three directions are shown in Table 8. Stress nephogram of subsystem in the $X$ direction is shown in Figure 12. The damping coefficient of Al-Li alloy plate is supposed to be $3 \%$ and its maximum acceleration response of all function devices in $X, Y$, and $Z$ directions is $17.4 G, 10.5 G$, and $19.6 G$, respectively.

Modal analysis is carried out after size optimization, and first two order modes of subsystem are with Al-Li alloy plate
TABLE 8: Maximum von Mises stress and deformation under input loads.

\begin{tabular}{lcc}
\hline Input loads & $\begin{array}{c}\text { Maximum von } \\
\text { Mises stress [MPa] }\end{array}$ & $\begin{array}{c}\text { Maximum } \\
\text { deformation } \\
{[\mathrm{mm}]}\end{array}$ \\
\hline $\begin{array}{l}X \text { direction: } 16.2 G \\
\text { acceleration field }\end{array}$ & 11.3 & 0.07868 \\
$Y$ direction: $12.9 G$ & 16.48 & 0.05293 \\
$\begin{array}{l}\text { acceleration field } \\
Z \text { direction: } 9.5 G\end{array}$ & 17.24 & 0.1687 \\
acceleration field & & \\
\hline
\end{tabular}

shown in Figure 13. Natural frequencies of first eight order modes are shown in Table 9. 

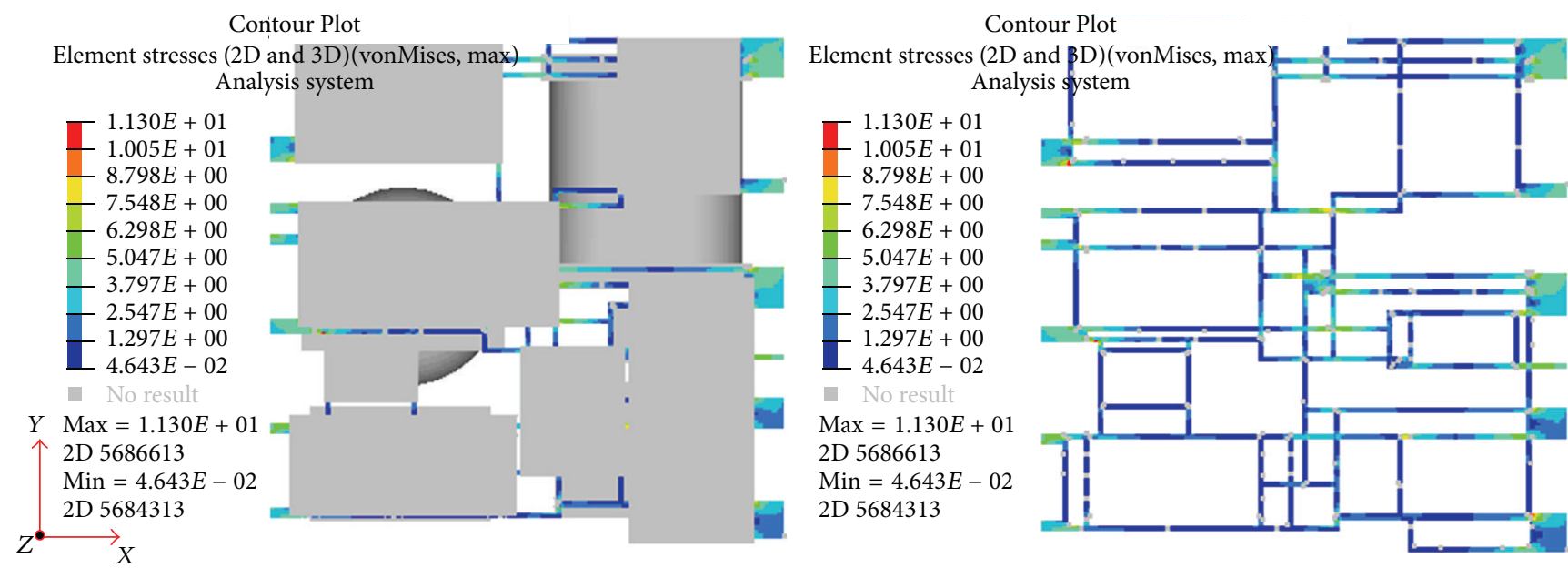

FIGURE 12: Stress nephogram of subsystem in the $X$ direction.

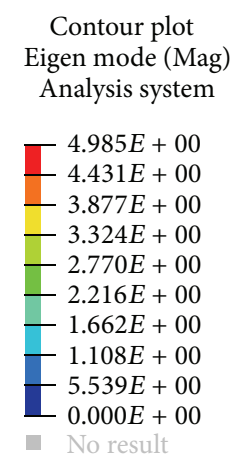

$\operatorname{Max}=4.985 E+00$ Grids 14804

$\operatorname{Min}=0.000 E+00$ Grids 115139

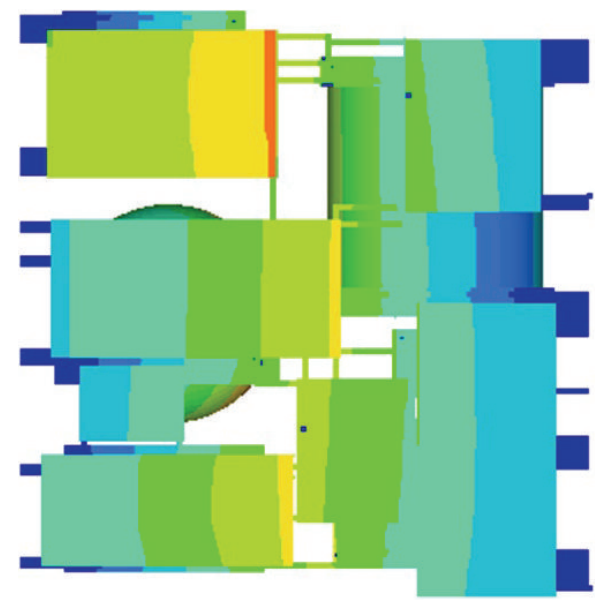

(a) First order mode

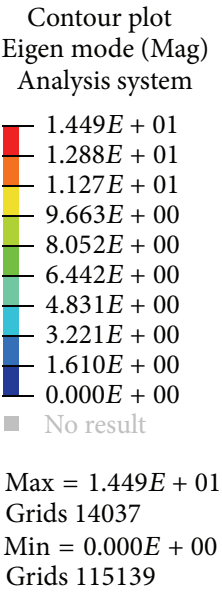

Grids 115139

FIgURE 13: First and second order mode of subsystem with Al-Li alloy plate.

TABLE 9: Natural frequencies of first eight order modes.

\begin{tabular}{lcccccccc}
\hline $\begin{array}{l}\text { Mode } \\
\text { order }\end{array}$ & 1 & 2 & 3 & 4 & 5 & 6 & 7 & 8 \\
\hline $\begin{array}{l}\text { Natural } \\
\text { frequency } \\
{[\mathrm{Hz}]}\end{array}$ & 115.3 & 190 & 215.2 & 251 & 186.9 & 279.6 & 294.3 & 317 \\
\hline
\end{tabular}

4.3. Comparative Analysis of Two Materials. After structural optimization, the optimized performance of two materials is obtained and shown in Table 10. All performance indices met the requirements and the eventual mass of $\mathrm{APH}$ is slightly lighter than Al-Li alloy. The first order modals of two structures are both the vibration perpendicular to the plate face ( $Z$ direction) and the deformation of $Z$ direction is maximum. The maximum von Mises stress of Al-Li alloy structure is much larger than that of honeycomb panel.
Fundamental frequency and harmonic response are almost same. As can be seen from the comparison results, the performance of honeycomb panel is slightly superior to AlLi alloy.

\section{Conclusion}

In order to compare the performance of Al-Li alloy and honeycomb panel which are both excellent materials for aeronautical structures, the mathematical models of structural optimization are established for these two distinctively different materials. Altair OptiStruct is used to carry out the optimized analysis. Honeycomb panel is seen as an integral structure and only size optimization is used to obtain its optimized heights. Topology and size optimization are applied to obtain the optimized configuration and thickness of the Al-Li alloy plate. The mass of optimized AHP including bolt sockets is $42.72 \mathrm{~kg}$ and that of Al-Li alloy plate is $48.39 \mathrm{~kg}$, 
TABLE 10: Comparative analysis of optimization results of two materials.

\begin{tabular}{lccc}
\hline Performance & Requirements & Optimization results of AHP & Optimization results of Al-Li alloy \\
\hline Maximum stress & $\leq 187 \mathrm{MPa}$ & $1.82 \mathrm{MPa}(X$ direction $)$ & $17.24 \mathrm{MPa}(Z$ direction $)$ \\
Maximum deformation & $\leq 0.3 \mathrm{~mm}$ & $0.19 \mathrm{~mm}(Z$ direction $)$ & $0.17 \mathrm{~mm}(Z$ direction $)$ \\
Fundamental frequency & $\geq 115 \mathrm{~Hz}$ & $114.8 \mathrm{~Hz}$ & $115.3 \mathrm{~Hz}$ \\
Harmonic response & $\leq 22 \mathrm{G}$ & $18.5 \mathrm{G}$ & $19.6 \mathrm{G}$ \\
Mass & Minimized mass & $42.72 \mathrm{~kg}$ & $48.39 \mathrm{~kg}$ \\
\hline
\end{tabular}

so AHP is superior to Al-Li alloy for weight reduction consideration. The optimization procedure shows that structural optimization is an excellent method for material selection in the conceptual design phase.

\section{Conflict of Interests}

The authors declare that there is no conflict of interests regarding the publication of this paper.

\section{Acknowledgment}

The authors would like to express their appreciation to National Natural Science Foundation of China (Grants nos. 51175505 and 51305455) for providing the financial support to this work.

\section{References}

[1] C. Giummarra, B. Thomas, and R. Rioja, "New aluminum lithium alloys for aerospace applications," in Proceedings of the 3rd International Light Metals Technology Conference, Bombardier Aerospace and Alcoa Trade Study, Québec, Canada, September 2007.

[2] R. R. Boyer, "An overview on the use of titanium in the aerospace industry," Materials Science and Engineering A, vol. 213, no. 1-2, pp. 103-114, 1996.

[3] M. Peters, J. Kumpfert, C. H. Ward, and C. Leyens, “Titanium alloys for aerospace applications," Advanced Engineering Materials, vol. 5, no. 6, pp. 419-427, 2003.

[4] E. C. Botelho, R. A. Silva, L. C. Pardini, and M. C. Rezende, "A review on the development and properties of continuous fiber/epoxy/aluminum hybrid composites for aircraft structures," Materials Research, vol. 9, no. 3, pp. 247-256, 2006.

[5] P. D. Mangalgiri, "Composite materials for aerospace applications," Bulletin of Materials Science, vol. 22, no. 3, pp. 657-664, 1999.

[6] R. J. Rioja and J. Liu, "The evolution of Al-Li base products for aerospace and space applications," Metallurgical and Materials Transactions A: Physical Metallurgy and Materials Science, vol. 43, no. 9, pp. 3325-3337, 2012.

[7] R. K. Gupta, N. Nayan, G. Nagasireesha, and S. C. Sharma, "Development and characterization of Al-Li alloys," Materials Science and Engineering A, vol. 420, no. 1-2, pp. 228-234, 2006.

[8] G. G. Galletti, C. Vinquist, and O. S. Es-Said, "Theoretical design and analysis of a honeycomb panel sandwich structure loaded in pure bending," Engineering Failure Analysis, vol. 15, no. 5, pp. 555-562, 2008.
[9] J. K. Paik, A. K. Thayamballi, and G. S. Kim, "Strength characteristics of aluminum honeycomb sandwich panels," Thin-Walled Structures, vol. 35, no. 3, pp. 205-231, 1999.

[10] B. J. Kim and D. G. Lee, "Development of a satellite structure with the sandwich T-joint," Composite Structures, vol. 92, no. 2, pp. 460-468, 2010.

[11] G. Bianchi, G. S. Aglietti, and G. Richardson, "Development of efficient and cost-effective spacecraft structures based on honeycomb panel assemblies," in Proceedings of the IEEE Aerospace Conference, pp. 1-10, Big Sky, Mont, USA, March 2010.

[12] L. Librescu and T. Hause, "Recent developments in the modeling and behavior of advanced sandwich constructions: a survey," Composite Structures, vol. 48, no. 1, pp. 1-17, 2000.

[13] Y. Lin, Z. Zheng, S. Li, X. Kong, and Y. Han, "Microstructures and properties of 2099 Al-Li alloy," Materials Characterization, vol. 84, pp. 88-99, 2013.

[14] A. R. Srinivas, Robust Design and Realization of Spacecraft Payload Elements Using Optistruct as an Optimization Tool, Space Application Centre ISRO, 2008.

[15] N. Noilublao and S. Bureerat, "Simultaneous topology, shape and sizing optimisation of a three-dimensional slender truss tower using multiobjective evolutionary algorithms," Computers \& Structures, vol. 89, no. 23-24, pp. 2531-2538, 2011.

[16] J. Zhu, W. Zhang, P. Beckers, Y. Chen, and Z. Guo, "Simultaneous design of components layout and supporting structures using coupled shape and topology optimization technique," Structural and Multidisciplinary Optimization, vol. 36, no. 1, pp. 29-41, 2008.

[17] A. S. Gendy, S. N. Patnaik, D. A. Hopkins, and L. Berke, "Optimization of Space Station components using design code CometBoards," Computer Methods in Applied Mechanics and Engineering, vol. 129, no. 1-2, pp. 133-149, 1996.

[18] S. Buchanan, "Development of a wingbox rib for a passenger jet aircraft using design optimization and constrained to traditional design and manufacture requirements," in Proceedings of the CAE Technology Conference, April 2007.

[19] P. L. Schoonover, W. A. Crossley, and S. D. Heister, "Application of a genetic algorithm to the optimization of hybrid rockets," Journal of Spacecraft and Rockets, vol. 37, no. 5, pp. 622-629, 2000.

[20] E. R. Taylor, "Evaluation of multidisciplinary design optimization techniques as applied to spacecraft design," in Proceedings of the IEEE Aerospace Conference Proceedings, vol.1, pp. 371-384, IEEE, Big Sky, Mont, USA, March 2000.

[21] K. Maute and M. Allen, "Conceptual design of aeroelastic structures by topology optimization," Structural and Multidisciplinary Optimization, vol. 27, no. 1-2, pp. 27-42, 2004.

[22] Z. Fang and L. Zheng, "Topology optimization for minimizing the resonant response of plates with constrained layer damping treatment," Shock and Vibration, vol. 2015, Article ID 376854, 11 pages, 2015. 
[23] N. S. Ermolaeva, M. B. G. Castro, and P. V. Kandachar, "Materials selection for an automotive structure by integrating structural optimization with environmental impact assessment," Materials \& Design, vol. 25, no. 8, pp. 689-698, 2004.

[24] W. Hansel and W. Becker, "Layerwise adaptive topology optimization of laminate structures," Engineering Computations (Swansea, Wales), vol. 16, no. 7, pp. 841-851, 1999.

[25] Altair Engineering Inc, Optistruct 8.0 User Manual, Altair Engineering Inc, 2007.

[26] H. G. Allen, Analysis and Design of Structural Sandwich Panels, Pergamon Press, Oxford, UK, 1969.

[27] A. K. Noor, W. S. Burton, and C. W. Bert, "Computational models for sandwich panels and shells," Applied Mechanics Reviews, vol. 49, no. 3, pp. 155-199, 1996. 


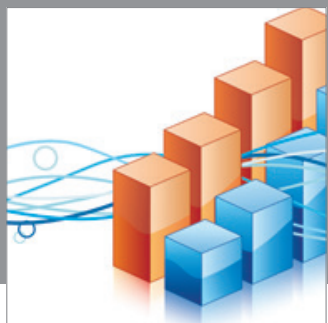

Advances in

Operations Research

mansans

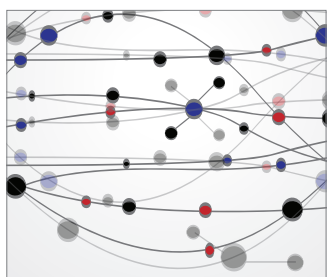

The Scientific World Journal
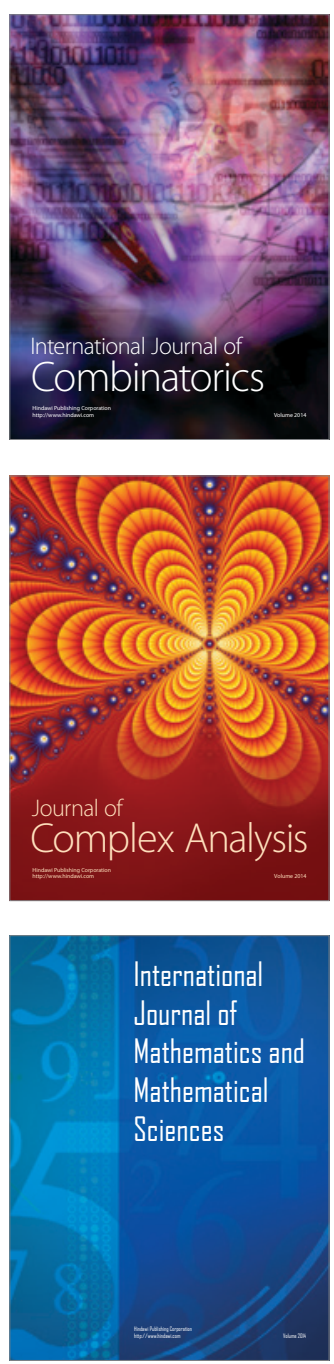
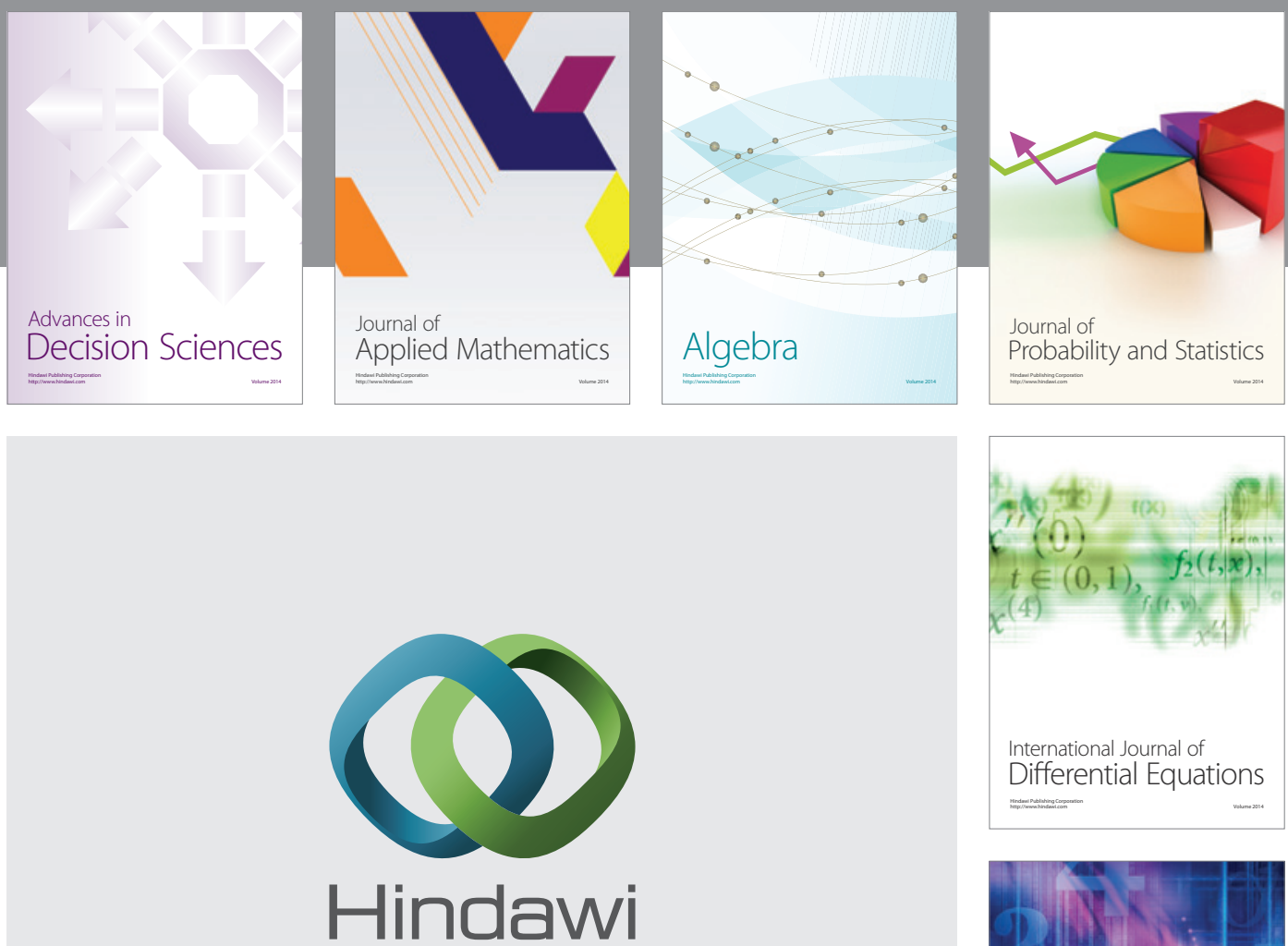

Submit your manuscripts at http://www.hindawi.com
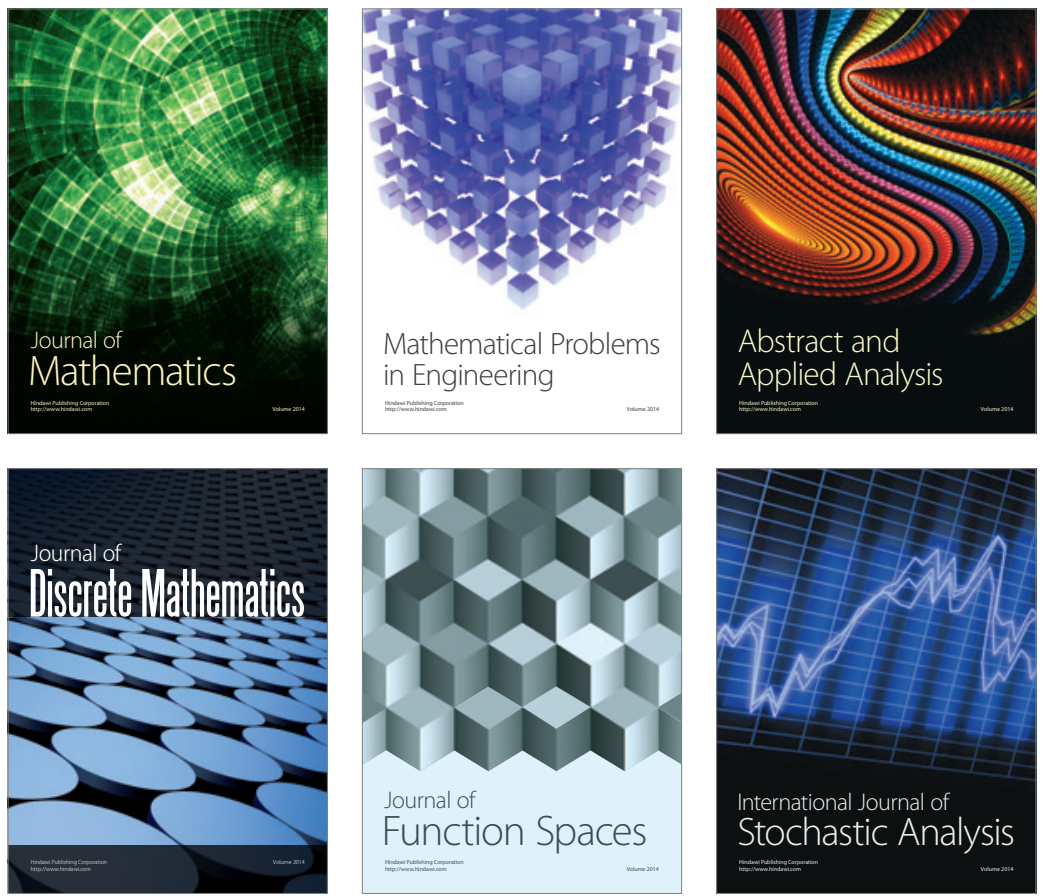

Journal of

Function Spaces

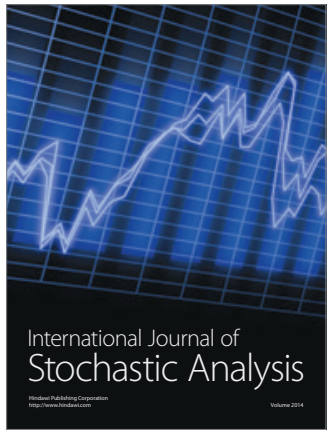

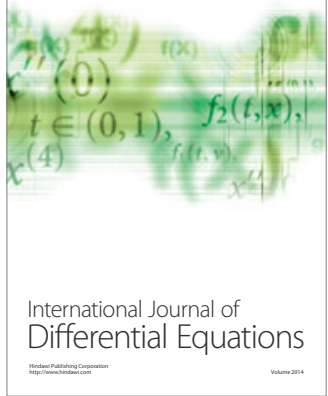
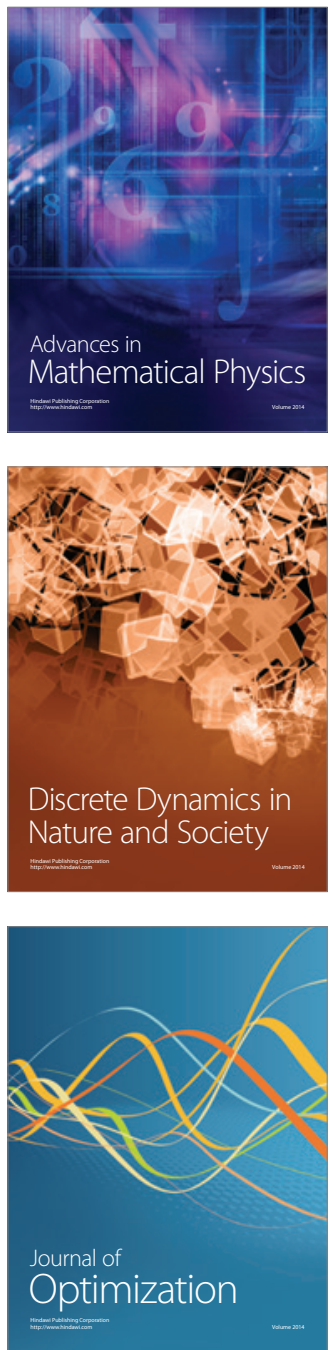